\title{
Roll-Up is too complex for Romanian 5-year-olds: Evidence from recursive adjectives
}

\author{
Adina Camelia Bleotu \& Tom Roeper*
}

\begin{abstract}
The current paper examines Romanian 5-year-olds' comprehension and production of recursive structures involving multiple adjectives such as florile mici mari 'flowers-the small big', i.e., "the big small flowers". On the basis of an experiment we conducted on 20 Romanian 5-year-olds, we show that children have the tendency to reduce recursion to coordination, the default interpretation at this stage of language acquisition. Moreover, children avoid producing recursive structures, preferring simpler forms instead, while they produce coordinative structures to a much higher extent. Since children's performance with recursive adjectives in Romanian seems to be worse than performance with recursive prepositional phrases (Bleotu 2020), we argue that this supports the idea that, unlike prepositional phrases, multiple adjectives in Romance are derived through the complex operation of Roll-Up (Cinque 1994, 2005, 2010).
\end{abstract}

Keywords. language acquisition; Romanian L1; adjectives; recursion; coordination; Roll-Up

1. Introduction. Multiple adjective modification has been investigated by many theoretical and language acquisition studies (e.g., Dixon 1982, Matthei 1982, Cinque 1994, 2005, 2010, Scott 2002, Bryant 2006, Scontras et al. 2017, a.o.). However, most of the literature has focused on Adjective Ordering Restrictions, i.e., orderings of multiple adjectives specifying different dimensions such as the adjective big specifying SIZE and the adjective red specifying COLOR in the big red apples. The literature has dealt to a much lesser extent with multiple adjectives specifying the same dimension such as the adjectives big and small, which both specify SIZE. Our study hopes to shed light on the latter issue through an experiment on the ordering of recursive adjectives (specifying the same dimension, namely SIZE). To this purpose, we tested how Romanian 5-year-olds comprehend and produce multiple adjective structures involving both recursion and coordination. We show that Romanian children tend to reduce recursion to coordination in the case of adjectives to a larger extent than with other structures (like Prepositional Phrases) or in other languages (like English). We then examine the results in light of Cinque's Roll-Up Theory (1994, 2005, 2010), arguing that the acquisition data support the idea that adjectives in Romance are derived through a complex operation (Roll-Up) resulting in the reverse order from English.

2. Multiple adjectives and Roll-Up Most of the research on adjective orderings focuses on adjectives which specify different properties, such as the adjectives in (1).

a beautiful small oval orange French vase

\footnotetext{
* The current work has been supported by the ISDS-UB postdoc project A Coloring Approach to how Children Understand Recursion in Romanian (supervised by Larisa Avram). We would like to thank the children and tutors at Waldorf Kindergarten (Bucharest) and the students at the University of Bucharest for taking part in the experiment. In addition, we would also like to give thanks to the audiences at UMass, BUCLD, LSA 2021 for their valuable comments and suggestions. Authors: Adina Camelia Bleotu, ISDS, University of Bucharest (cameliableotu@gmail.com) \& Tom Roeper, UMass Amherst (roeper@linguist.umass.edu).
} 
Various ordering generalizations have been proposed in the literature (see 2):
a. VALUE > DIMENSION > PHYSICAL PROPERTY > SPEED > HUMAN PROPENSITY $>\quad$ AGE $>$ COLOR (Dixon 1982)
b. SUBJECTIVE COMMENT > SIZE > LENGTH > HEIGHT > SPEED > WIDTH > WEIGHT $>$ TEMPERATURE $>$ AGE $>$ SHAPE $>$ COLOR $>$ NATIONALITY/ORIGIN $>$ MATERIAL (Scott 2002)
c. QUALITY > SIZE > SHAPE > COLOR > PROVENANCE (Sproat \& Shih 1991)
d. SUBJECTIVE> NON-SUBJECTIVE (Scontras et al. 2017)

These orderings have been given syntactic, semantic or pragmatic interpretations, ascribing different sources to the hierarchies which seem to surface across languages.

Interestingly, it has been proposed that Romance languages exhibit a mirror image of the order of adjectives in English (3a). This is exemplified for Romanian in (3b).
a. a small orange French vase
b. o vază franceză portocalie mică
a vase French orange small
'a small orange French vase'

Two major syntactic accounts have been proposed in the literature in order to capture this mirror effect (Nevins 2011). On the one hand, we have the Adjunction account (Abels \& Neeleman 2010), according to which the difference between English and Romance can be accounted for by arguing that adjectives are left-adjoined in English, but they are right-adjoined in Romanian, as one can see in (4a). On the other hand, there is the Roll-Up cartographic account (Cinque 1994, 2005,2010 ), according to which adjectives occur in a certain basic syntactic order in English, while they occur in the reverse order in Romance as a consequence of the complex operation of Roll-Up. The order of adjectives in English reflects the actual ordering of syntactic projections: Each adjective specifying a certain dimension marks a different projection in the sequence. In contrast, in Romance languages, the surface order is a result of a sequence of movement operations. For instance, in (4), the NP moves out of its position to an outer specifier (Step 1), the newly formed FP containing FP nationality moves out of its position to the outer specifier of the next $\mathrm{FP}_{\text {color }}$ (Step 2), and then the newly formed FP containing the N, $\mathrm{FP}_{\text {nationality }}$ and $\mathrm{FP}_{\text {color }}$ (Step 3) moves to the outer specifier of the projection hosting FP size. Thus, the order in (4b) is derived. While both accounts can capture the differences in adjective orderings between English and Romance, the Adjunction account does not provide a principled syntactic motivation for why adjectives occur in this basic order, while Roll-Up offers a syntactic grounding for the ordering. However, it has been claimed that adjective ordering restrictions might not be innate hierarchies as claimed by Cinque (1994, 2005, 2010), given that Romance languages and Greek seem to allow for freer word orders (see Cornilescu \& Nicolae 2016, Leivada \& Westergaard 2019). This might be thought to pose problems for the Roll-Up Approach and favor the Adjunction approach. Nevertheless, the matter remains inconclusive, since some freer orders may be explicable through FOCUS. 
(4)

Adjunction

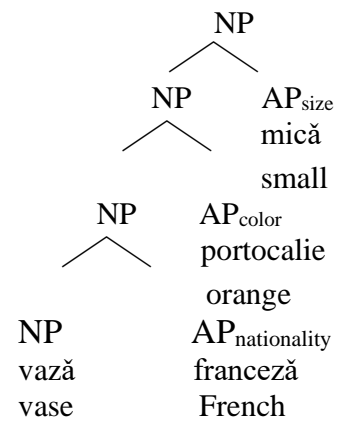

Roll-Up

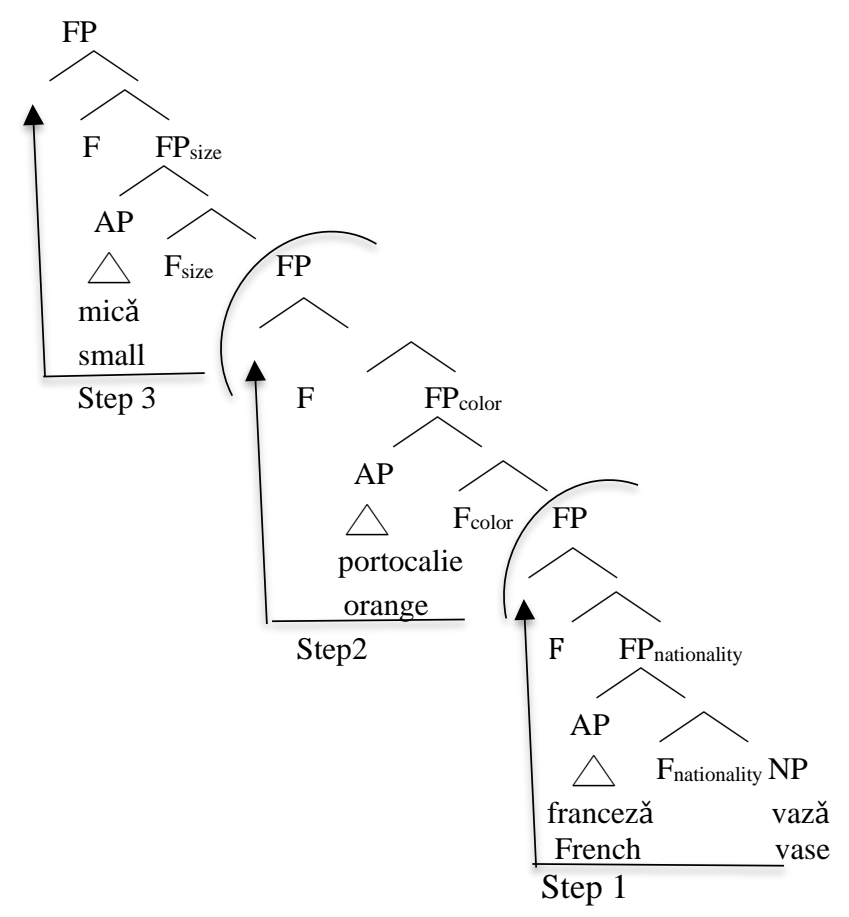

Interestingly, even if one embraces the view that adjectives specifying different dimensions are freely ordered, this does not apply to adjectives specifying the same dimension. Recursive adjectives are ordered depending on the set they pick, such that supersets are closer to the head noun than sets. This leads to the Set-Superset-Noun ordering in English, but the N-Superset-Set ordering in Romanian, for instance (see 5). Both Adjunction and Roll-Up are able to derive such orders.

(5)

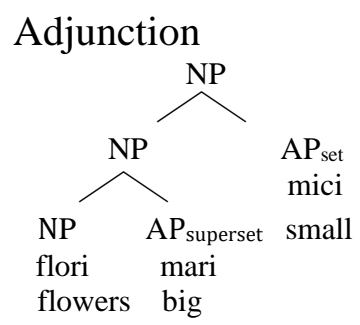

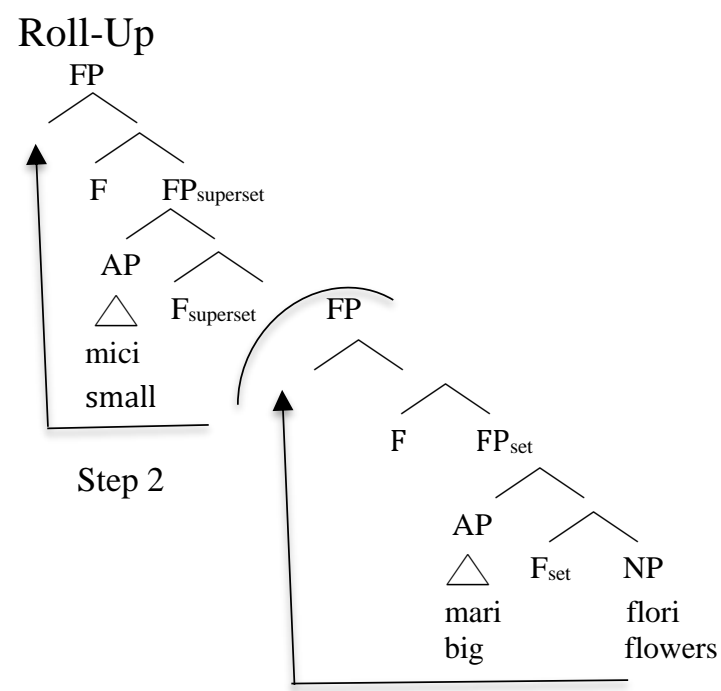

Step 1

Language acquisition can provide insights into which theoretical account best captures the linguistic data. Language acquisition studies show that children handle multiple adjectives in a 
different manner from adults. As far as adjective ordering restrictions are concerned, English children younger than 5 do not yet seem to order adjectives in a consistent way (see Lee et al. 2018). Moreover, as far as multiple recursive adjectives are concerned, there is evidence from CHILDES that children first use multiple adjectives in coordination ([Adam 2.3]: I funny little boy) and only later use them recursively ([Adam 3, 4]: he got a little big trailer.) (Gu 2008). The tendency to prefer coordination over recursion can also be seen in comprehension. Matthei (1982) and Bryant (2006) have shown that 4-year-olds children interpret recursive structures as coordinative (the second green ball as 'the second and the green ball' rather than 'the second of the green balls', big black balls as 'big and black balls' rather than 'the big of the black balls'). However, around the age of 5, children start handling multiple adjectives in a more adult-like manner (see Lee et al. 2018), although their performance is not yet adult-like.

The situation in a Romance language like Romanian is even more complex, given that recursion is further complicated by the fact that adjectives occur in a mirror order in comparison to English. Recursion with adjectives has never been investigated experimentally in child Romanian so far, but looking at how children performed with recursive prepositional phrases might give us some insight into what to expect. Sevcenco \& Avram (2018) previously investigated recursion with prepositional phrases (PPs) in Romanian through an act-out task where children had to arrange some animals on an iPad after hearing a sequence such as the lion by the zebra by the bear. They showed that Romanian 5-year-old children handle recursive PPs $(40.33 \%)$ in a more adult-like manner than English children (25.44\%). Moreover, Bleotu (2020) showed that Romanian children perform even more adult-like $(77.17 \%)$ when they are exposed to both recursion and coordination in the same picture selection task. Children were more accurate in their picture choices (see Figure 1), given that the contrast between recursion and coordination enhances their awareness of the differences between the two structures (see 6a versus 6b). Importantly, however, PPs in Romanian do not surface in a mirror order compared to PPs in English, but actually in the exact same order as in English:
a. Papagalul de lângă hamsterul de lângă iepuraş este roşu. parrot-the de next.to hamster-the. de next.to bunny is red 'The parrot next to the hamster next to the bunny is red.'
b. Papagalul de lângă hamster şi de lângă iepuraş este roşu. parrot-the de next.to hamster-the. and de next.to bunny is red 'The parrot next to the hamster and next to the bunny is red.'

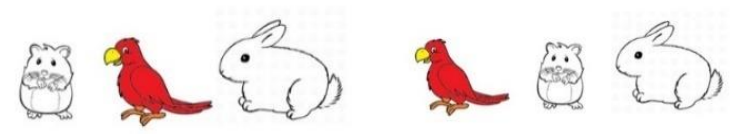

Figure 1. Examples of pictures used in Bleotu (2020)

If multiple adjectives are simply adjoined to the left rather than to the right, as in English, then we expect children to handle recursive adjectives in the same way as recursive PPs. If Roll-Up complicates the derivation of multiple adjectives, we expect children to handle recursive adjectives worse than PPs. Thus, we expect them to misrepresent recursive structures as coordinative structures of the kind in (7) (see Goodall 2007). While (7) is just one representation of coordination among many possible ones, it is nevertheless representative for the simplicity of the structure in comparison to the intricacies of Roll-Up. Our paper tests such expectations from an experimental point of view, on the basis of language acquisition data from Romanian. 
(7)

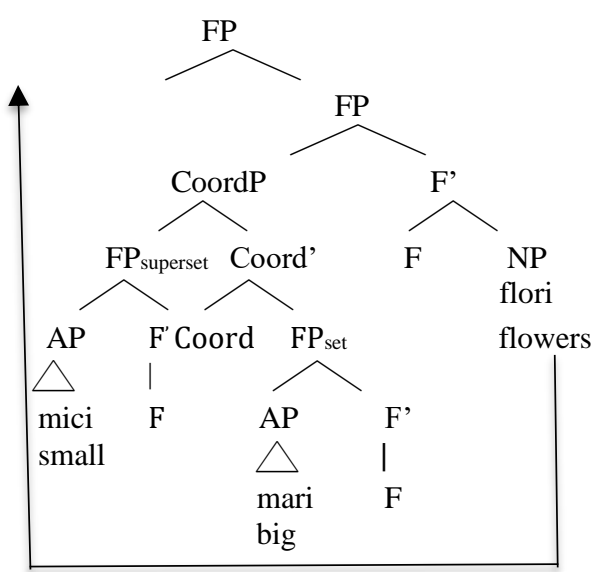

3. Experiment. The current experiment explores how Romanian 5-year-olds handle multiple recursive and coordinative adjectives in comprehension and production.

3.1. PARTICIPANTS. A test group of 20 Romanian monolingual TD children (Age range: 4; 11-6;4, Mean age: 5;35, M=10, $\mathrm{F}=10$ ) and a control group of 20 adults took part in the task.

3.2. PREDICTIONS. Based on previous findings about recursion in language acquisition, showing that coordination is the default for recursion (Matthei 1982, Bryant 2006, Hollebrandse et al. 2008, Roeper et al. 2012, Pérez-Leroux et al. 2012, Hollebrandse \& Roeper 2014, Sevcenco et al. 2017, Sevcenco \& Avram 2018, Daoxin et al. 2020, a.o.), we predict that children will often interpret recursive adjectives as coordinative rather than as recursive. In fact, they may do so to an even higher extent than with other types of recursion (such as PP-recursion) if we assume that, unlike other recursive structures, recursive adjectives in Romanian are derived via Roll-Up rather than adjunction. Moreover, children may avoid producing recursive structures, and, instead, they might opt for simpler forms, while they should have no problems producing coordinative structures.

3.3. PROCEDURE. Children were asked to help a girl find certain objects/animals for her grandma after hearing various structures. The experiment involved a training session and a testing session. In the training session, children drew circles and squares around various objects in order to become familiar with the experimental procedure. In the testing session, children were presented with 2 (out of 4) picture sets on an iPad, representing 16 flowers (mare 'big'/mic 'small'), giraffes (inalt 'tall'/scund 'short'), blades of grass (lung 'long'/scurt 'short'), squirrels ( gras 'fat'/slab 'thin') (see Figure 2 for an example).

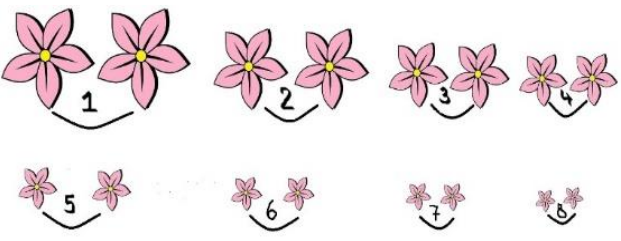

Figure 2. Example of a picture set (with numbers added)

The testing session involved both questions about the comprehension and questions about the production of multiple adjectives in recursive and coordinative structures (see Table 1 for a full list of items tested for one picture set). In comprehension, children were asked to draw circles around sets of objects/animals, a method which builds upon the drawing method by Austin Tero 
and Emma Merritt (UMass Amherst). In production, children were asked to name sets of objects/animals. For instance, children were first presented with the flowers in Figure 2: "Look, these are big flowers (1-4) and these are small flowers (5-8)". When tested for comprehension, children heard: "Let's look at the big flowers now. Among the big flowers, some flowers are bigger and some flowers smaller. You see, these flowers (4) are smaller than these (3) are, and these flowers (3) are bigger than them (4). Can you show me the small big flowers (3-4), can you draw a green circle around them?". When tested for production, children heard: "If these are small small big flowers (4), how can we call these small big flowers which are bigger than the others? (the big small big flowers) (3)".

\begin{tabular}{|c|c|c|c|c|}
\hline Level & Comprehension & Production & Comprehension & Production \\
\hline $\begin{array}{c}\text { I } \\
(2 \\
\text { adj) }\end{array}$ & $\begin{array}{l}\text { flori mari mici (3-4) } \\
\text { flowers big small } \\
\text { 'small big flowers' } \\
\text { flori mici mici (7-8) } \\
\text { flowers small small } \\
\text { 'small small flowers' }\end{array}$ & $\begin{array}{l}\text { flori mari mari } \\
(1-2) \\
\text { flowers big big } \\
\text { 'big big flowers' } \\
\text { flori mici mari } \\
(5-6) \\
\text { flowers small big } \\
\text { 'big small flowers' }\end{array}$ & $\begin{array}{l}\text { flori mari şi } \\
\text { mici }(1-4,5-8) \\
\text { flowers big and } \\
\text { small } \\
\text { 'big and small } \\
\text { flowers' }\end{array}$ & $\begin{array}{l}\text { flori mici } \\
\text { şi mari (5-8, } \\
1-4) \\
\text { flowers small } \\
\text { and big } \\
\text { 'small and big } \\
\text { flowers' }\end{array}$ \\
\hline $\begin{array}{c}\text { II } \\
(3 \\
\text { adj) }\end{array}$ & $\begin{array}{l}\text { flori mari mici mici (4) } \\
\text { flowers big small small } \\
\text { 'small small big flowers' } \\
\text { flori mici mici mari (7) } \\
\text { flowers small small big } \\
\text { 'big small small flowers }\end{array}$ & $\begin{array}{l}\text { flori mari mici } \\
\text { mari (3) } \\
\text { flowers big small } \\
\text { big } \\
\text { 'big small big } \\
\text { flowers' }\end{array}$ & $\begin{array}{l}\text { flori mari mici } \\
\text { şi mici (3-4, 5-8) } \\
\text { flowers big small } \\
\text { and small } \\
\text { 'small big and } \\
\text { small flowers' } \\
\text { flori mari şi } \\
\text { mici mici (1-4, 7- } \\
\text { 8) } \\
\text { flowers big and } \\
\text { small small } \\
\text { 'big and small } \\
\text { small flowers' } \\
\text { flori mari şi } \\
\text { mici şi mici (1- } \\
4,5-8) \\
\text { flowers big and } \\
\text { small and small } \\
\text { 'big and small } \\
\text { and small flow- } \\
\text { ers' (1-8) }\end{array}$ & $\begin{array}{l}\text { flori mari } \\
\text { şi mici } \\
\text { mari }(1-4,5-6) \\
\text { flowers big } \\
\text { and small big } \\
\text { 'big and big } \\
\text { small flowers' }\end{array}$ \\
\hline
\end{tabular}

Table 1. Example of one list of test items for comprehension and production

3.4. RESULTS Adults performed close to ceiling with recursive and simple coordinative structures in both comprehension and production. In contrast, as one can see in Figure 3, children performed more adult-like with simple coordination than with recursive structures. Nevertheless, both adults and children performed worse with structures combining coordination and recursion such as florile mari mici şi mici 'the small big and small flowers' (labelled as CoordMixed in Figure 3). 


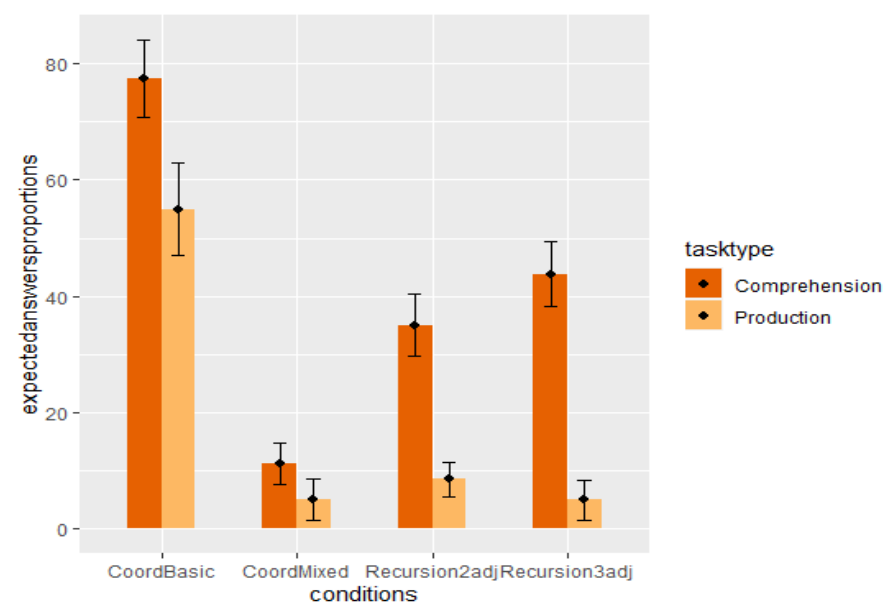

Figure 3. Children's answers for comprehension and production of coordination and recursion

In order to evaluate the data statistically, we used R (2018) and fitted a mixed effects model with Error as a dependent variable, group (children/adults), expected reading (coordination/recursion), type of task (comprehension/production) and the interaction between group and expected reading and between group and task type as fixed effects, and random slopes per item (flower/squirrel/blades of grass/squirrels) and participants. We compared recursion to simple coordination by using the Helmert coding scheme: recursion $=1$, coordination $=-1$, mixed coordination $=0$. We found significant differences between adults and children $(\beta=1.843$, $S E=0.3244, Z=5.683, p<0.001)$, coordination and recursion $(\beta=-1.706, S E=0.214$, $Z=-7.96, p<0.001)$, comprehension and production $(\beta=-3.659, S E=1.139, Z=-3.212$, $p<0.005)$, as well as a significant interaction between group and expected reading $(\beta=1.827$, $S E=0.248, Z=7.375, p<0.001)$, and a significant interaction between group and task type ( $\beta=4.4, S E=1.164, Z=3.78, p<0.001$ ). We also compared recursion to mixed coordination through the Helmert coding scheme: recursion $=1$, mixed coordination $=-1$, simple coordination $=0$, and we found that the interaction between group and expected reading is somewhat less significant ( $\beta=4.99, S E=2.38, Z=2.099, p=0.036$ ).

In the comprehension of recursion, children gave a variety of non-adult-like answers: mostly coordinative answers (see 8a), as well as answers picking larger sets (the large set defined by the first adjective in the case of sequences of two or three adjectives or even the first two adjectives in the case of sequences of three adjectives-see 8b) or answers picking subsets of the actual set or an unexpected set. Interestingly, in the case of sequences involving two adjectives, children gave a lot of intensifier answers, interpreting florile mici mici 'small small flowers' as 'very small flowers', 'the smallest flowers'. The intensifier reading is available to adults as well, but children seem to prefer it to a much higher extent (three times as much as adults).
a. Expected:
veveriţele slabe grase
squirrels-the thin fat
'the fat thin squirrels'
b. Expected:
girafele inalte scunde scunde giraffes-the tall short short
'the short short tall giraffes'

Answer:

veveriţele slabe şi grase squirrels-the thin and fat 'the thin and fat squirrels'

Answer:

girafele inalte scunde giraffes-the tall short 'the short tall giraffes' 
In the comprehension of coordination, children were quite adult-like with simple coordination, but not with mixed coordination, which combines coordination with recursion, where even adults' performance was quite low $(67.5 \%)$. Children mostly reduced mixed coordination to simple coordination (9a), but they sometimes interpreted it as recursion (9b) or even gave one adjective answers.

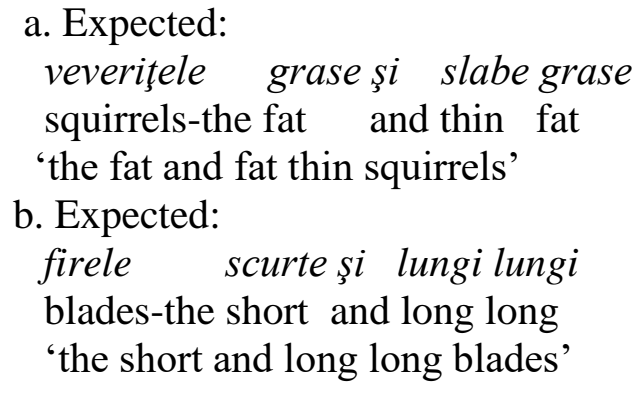

Answer:

veveriţele slabe şi grase
squirrels-the thin and fat
'the thin and fat squirrels'
Answer:
firele scurte lungi lungi
blades-the short long long
'the long long short blades'

Children's performance in production was much lower than in comprehension. In the production of recursion, children opted for simpler forms such as nouns followed by one adjective (simple, comparative or superlative forms) or two adjectives instead of three, as well as simple nouns (denoting the veveriţe 'squirrels') or invented nouns (ninja instead of veveriţe 'squirrels').

In the production of coordination, children produced $47.5 \%$ correct answers with simple coordination but only $5 \%$ correct ones with mixed coordination. Moreover, children often failed to give an answer altogether, explaining that they did not know what to say. There were $22.5 \%$ missing answers for simple coordination and 37.5\% missing answers for mixed coordination. The errors children produced in the case of simple coordination were nouns followed by one single adjective (often indicating subsets), simple nouns, invented nouns, whereas, in the case of mixed coordination, they often used coordination between other sets than expected (a superset, for instance-see 10) or nouns followed by simple adjectives.

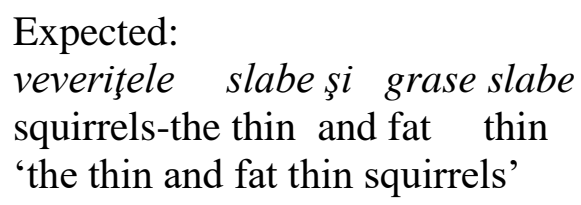

Answer:

veveriţe mari şi mici squirrels big and small 'big and small squirrels'

4. Discussion. The results show that children tend to reduce recursion to coordination, often interpreting recursive structures as coordinative, while reducing coordination to recursion to a much lesser extent. This asymmetry suggests that coordination is the default, representing a simpler option for children both from a semantic and syntactic perspective. Interestingly, in production, children manage to produce coordinative structures much more, which supports the idea of the primacy of coordination.

From a semantic point of view, recursive structures are more complex, involving functional application (see Weicker 2019): The interpretation requires applying properties to sets in order to create subsets. For instance, the sequence flori mici mari 'big small flowers' is interpreted by adults as [big [small flowers]], thus picking the big flowers relative to the set of small flowers. In contrast, coordinative structures are simpler, requiring predicate modification, more exactly, coordination among two sets ([[big and small] flowers]). Interestingly, in contrast to adults, children seem to interpret recursive structures in a coordinative manner, choosing to coordinate rather than to create subsets. 
From a syntactic point of view, we propose that acquisition takes into account Hierarchies of Syntactic Complexity, such as:

\section{(11) \\ Roll-Up > XP Movement >Head Movement> No Movement/External Merge}

Children prefer No Movement or XP-Movement over Roll-Up, a complex operation which involves various movements. Apart from relying on Movement over No Movement, the complexity of Roll-Up is related to the complexity of the XP that undergoes movement, a heavy XP with a rich internal structure. Unlike simple XP-Movement, Roll-Up is burdensome, and, hence, dispreferred by children. The logic of the argument builds on the idea that what matters is not simply what kind of operation children resort to (Movement/No Movement), but also what is moved or merged. Children prefer No Movement to Movement, but, in case they do need to move, they prefer moving simpler constituents over moving more complex ones. Since deriving coordination in Romanian seems to involve Merge and one XP-Movement (more specifically, one NP-movement), unlike recursion, which involves Merge and Roll-Up (i.e., several complex XP-movements)-see the representations in (5) and (7), this explains children's representation of recursion as coordination and their general ease with coordination.

In addition, we compare adjectival recursion to prepositional phrase recursion in Romanian. As already previously mentioned, recursive PPs occur in the same order in Romanian as they do in English (see 6). Importantly, they are not derived via Roll-Up, but through adjunction. Interestingly, Bleotu (2020) found that children handled PP-recursion in an adult-like manner (77.17\%). Comparing the results of the experiment from Bleotu (2020) and the results of the current experiment, we observe more accuracy with structures involving two PPs than with structures involving two adjectives (35\%). Importantly, while only 6 children were consistently recursive in their handling of adjectival recursive structures, 18 children out of 24 were consistently adult-like in their interpretation of recursive prepositional phrases. This contrast in performance supports the idea that Roll-Up provides a greater challenge for the acquisition path, since, if both adjectives and PPs were derived in the same way, we would have expected a similar behavior.

5. Conclusion In conclusion, in the current paper, we have provided experimental evidence from child Romanian that Romanian 5-year-olds face challenges in handling adjectival recursive structures, while being more adult-like in handling adjectival coordinative structures. Essentially, children tend to reduce recursion to coordination in comprehension, while avoiding recursive structures in production in favor of simpler linguistic forms. Children's difficulties with adjectival recursion (as opposed to their more adult-like handling of PP-recursion) are best understood by embracing the view that recursive adjectives in Romanian are derived via Roll-Up, unlike recursive PPs, which are derived via adjunction.

\section{References}

Abels, Klaus \& Ad Neeleman. 2010. Linear asymmetries and the LCA. Syntax 12(1). 25-74. https://doi.org/10.1111/j.1467-9612.2011.00163.x.

Bleotu, Adina C. 2020. The parrot next to the hamster (and) next to the bunny brings evidence for recursion in children. Presented at Societas Linguistica Europaea. https://osf.io/q6zj4.

Bryant, Doreen. 2006. Koordinationsellipsen in Spracherwerb: die Verarbeitung Potentieller Gapping Strukturn. Humboldt University Dissertation.

Cinque, Guglielmo. 1994. On the evidence for partial N-movement in the Romance DP. In Guglielmo Cinque, Jan Koster, Jean-Yves Pollock, Luigi Rizzi \& Raffaella Zanuttini (eds.), Paths 
towards Universal Grammar. Studies in Honor of Richard S. Kayne. 85-110. Washington DC: Georgetown University Press. https://doi.org/10.1353/lan.2001.0097.

Cinque, Guglielmo. 2005. Deriving Greenberg's Universal 20 and its exceptions. Linguistic Inquiry 36(3). 315-332. https://doi.org/10.1162/0024389054396917.

Cinque, Guglielmo. 2010. The syntax of adjectives. A comparative study. Cambridge: MIT Press.

Cornilescu, Alexandra \& Alexandru Nicolae. 2016. Romanian adjectives at the Syntax-semantics interface. Acta Linguistica Hungarica 63(2). 197-240. https://doi.org/10.1556/064.2016.63.2.3.

Dixon, Robert M. W. 1982. 'Where have all the adjectives gone?' and other essays in semantics and syntax. Berlin: Mouton de Gruyter.

Goodall, Grant. 2017. Coordination in Syntax. Oxford Research Encyclopedia of Linguistics. https://doi.org/10.1093/acrefore/9780199384655.013.36.

$\mathrm{Gu}$, Chloe. 2008. Structural ambiguity and AP/PP recursion in language acquisition. Ms., University of Massachusetts.

Hollebrandse, Bart, Kathryn Hobbs, Jill De Villiers \& Tom Roeper. 2008. Second order embedding and second order false belief. In João Freitas \& Anna Gavarró (eds.), Language acquisition and development, 268-278. Cambridge, UK: Cambridge Scholars Publishing.

Hollebrandse, Bart \& Tom Roeper. 2014. Empirical results and formal approaches to recursion in acquisition. In Tom Roeper \& Margaret Speas (eds.), Recursion: Complexity in cognition, 179220. Dordrecht: Springer. https://doi.org/10.1007/978-3-319-05086-7.

Lee, Sarah, Gregory Scontras \& Lisa Pearl. 2018. How adjective ordering preferences develop in children. Retrieved from www.socsci.uci.edu.

Leivada, Evelina \& Marit Westergaard. 2019. Universal linguistic hierarchies are not innately wired. Evidence from multiple adjectives. PeerJ 7. e7438. https://doi.org/10.7717/peerj.7438.

Limbach, Maxi \& Dani Adone. 2010. Language acquisition of recursive possessives in English. In Katie Franich, Kate M. Iserman \& Lauren L. Keil (eds.). Proceedings of the 34th annual Boston University Conference on Language Development, 281-290. Somerville, MA: Cascadilla Press.

Matthei, Edward H. 1982. The acquisition of prenominal modifier sequences. Cognition 11(3). 301-332. https://doi.org/10.1016/0010-0277(82)90018-X.

Nevins, Andrew. 2011. Convergent evidence for rolling up Catalan adjectives. Linguistic Inquiry 42(2). 339-345. https://doi.org/10.1162/LING_a_00044.

Pérez-Leroux, Ana Teresa, Anny P. Castilla-Earles, Susana Béjar, \& Diane Massam. 2012. Elmo’s sister's ball: The problem of acquiring nominal recursion. Language Acquisition 19(4). 301-311.https://doi.org/10.1080/10489223.2012.685019.

R Core Team. 2018. R: A language and environment for statistical computing. R Foundation for Statistical Computing. Vienna, Austria. Available online at https://www.R-project.org/.

Roeper, Tom. 2011. The acquisition of recursion: How formalism articulates the child's path. Biolinguistics 5(1-2). 57-86.

Roeper, Tom, Akiko Terunuma \& Terue Nakato. 2012. Acquisition of recursive possessives in Japanese. Ms. University of Massachusetts, Amherst.

Scontras, Gregory, Maria Polinsky, C.-Y. Edwin Tsai \& Kenneth Mai. 2017. Cross-linguistic scope ambiguity: When two systems meet. Glossa: A Journal of General Linguistics 2(1). 36. https://doi.org/10.5334/gjgl.198.

Scott, Gary-John. 2002. Stacked adjectival modification and the structure of nominal phrases. In Guglielmo Cinque (ed.), Functional structure in DP and IP: The cartography of syntactic structures, 91-120. New York: Oxford University Press. 
Sevcenco, Anca, Tom Roeper \& Barbara Pearson-Zurer. 2017. The Acquisition of recursive locative PPs and relative clauses in child English. In Choi Jiyoung, Hamida Demirdache, Oana Lungu \& Laurence Voeltzel (eds.), Language acquisition at the interfaces. Proceedings of GALA 2015, 287-301. Newcastle upon Tyne: Cambridge Scholars Publishing.

Sevcenco, Anca \& Larisa Avram. 2018. On the comprehension of recursive nominal modifiers in child Romanian. In Anna Gavarró (ed.), On the acquisition of the syntax of Romance, 259277. Amsterdam: John Benjamins [LALD 62]. https://doi.org/10.1075/lald.62.

Sproat Richard \& Chilin Shih. 1991. The cross-linguistic distribution of adjective ordering restrictions. In Carol Georgopoulos \& Roberta Ishihara (eds.), Interdisciplinary approaches to language, 565-593. Dordrecht: Kluwer. https://doi.org/10.1007/978-94-011-3818-5.

Weicker, Merle. 2019. The role of semantic complexity for the acquisition of adjectives. Frankfurt am Main: Goethe Universität dissertation. 